onanism from his seventeenth to his twenty-first year, but not excessively. Has strong sexual desires. Fondled with the object of his affections for more than two years before marriage without any gratification of his passions. Has never had sexual intercourse but frequently experienced nocturnal emissions. Mar ried ten days ago and has not been able to consummate the marriage rite because the erections were feeble and lacked in intromittent power. By careful examination no stricture was detected but there existed a very hyperesthetic condition of the urethra, especially sensitive in the prostatic portion. A steel sound was passed twice a week for a period of twentyone days, and he was instructed not to fondle his wife nor occupy the same apartment with her.

At the end of three weeks, the hyperesthesia of the urethra had been very much improved; I ligated the dorsal vein, although it was not enlarged. He was strictly enjoined not to attempt coitus for another month. At the expiration of this time intercourse was performed successfully and he has never experienced any difficulty since that time, now more than a year ago, in commanding an erection,

Case 4. - A bookkeeper, 31 years of age, who had masturbated for 7 years, on an average of twelve times in a week. Three years ago he abandoned masturbation and has since suffered from frequent nocturnal emissions, although he had not experienced an erection for many months and had no desire for sexual intercourse. His genital organs were small, pale and flabby. He was anemic, weak and neurasthenic. He had read "lost manhood restored" literature until he believed he could never be cured. I was convinced of that, but did not express it. He was a typical sexual hypochondriac.

On examination I found a stricture, caliber 18 French, four and one-half inches from the meatus, in addition to an extremely sensitive urethra, especially about the neck of the bladder. Under gradual dilatation the stricture and sensitive urethra were cured. With tonic treatment, cold douches to the perineum and good hygiene, his nightly emissions ceased in number and his confidence was somewhat restored. Although he was not a proper case for operation, I ligated the dorsal vein, more for the mental effect I hoped it would have than any hope of permanent cure. His condition did not improve. The bad habits of his past life so preyed upon his mind that he became more gloomy, disheartened and despondent. $\mathrm{He}$ drifted out of my care and left the community, therefore his subsequent history was lost, but I feel satisfied the operation did him no good.

Case 5. School teacher, 25 years of age, unmarried; had practiced masturbation from his fifteenth to his nineteenth year; suffered some from nocturnal emissions; has welldeveloped genital organs. No stricture, no hyperesthesia of urethra. He had attempted coitus on frequent occasions but they were all attended by failure on account of feeble erections. He was in robust health and had strong sexual pas sions. Was engaged to be married in a few months but his impotent condition so preyed upon his mind that he was on the eve of breaking the engagement when he consulted me. The dorsal vein being large and prominent I suggested ligating it and explained the theory. He readily consented and the operation was performed. I warned him against dallying or toying with women and advised him to marry his betrothed at once. He did so and all attempts since then at sexual intercourse have been crowned with success.

In conclusion I wish to state that under proper treatment, long continued, Case No. 3 would, I believe, have recovered without the operation. In the foregoing cases, excepting No. 4, the mental effect of the operation was simply wonderful. They felt positive they were cured and wanted to try their powers at once. Two of them were restrained with difficulty. We see so many cases of impotence due only to a fear of sexual incapacity. If we can restore confidence in this class of patients there is very little trouble experienced in establishing a cure, and I am inclined to believe a great many cases of psychic impotence can be cured by ligating the dorsal vein of the penis.

London's Growth. - Returns show that over 1,200 houses are erected monthly and from August 1896 to August 1897, 14,591 houses were built. Alterations and additions are nut noted.

\section{GANGRENE OF THE FOOT DUE TO UTERINE MYOMA.}

Presented to the Section on Surgery and Anatomy, at the Forty-eighth Annual Meeting of the American Medical Association, held at Philadelphia, Pr., June 1-4, 1897.

BY STEPHEN H. WEEKS, A.M., M.D.

PROFESSOR OF SURGERY IN THE MEDICAL SCHOOL OF MAINE. PORTLAND, ME.

The case which I am about to report is so unique in my experience, that I deem it worthy of publication.

Mrs. M. came to the Maine General Hospital with the following history: During the fall of 1895 and the early part of the winter of 1896 the patient suffered from severe cramps below the knee. It was mostly after sitting for a long time or after sleeping at night. In March, 1896, a slight cold was taken and she suffered much pain, which seemed like the pain of rheumatism. She soon became lame and suffered more pain in the limb, which could be relieved for a time by the application of dry heat. In the early part of June, the limb was so painful and lame that she was obliged to lie in bed. The limb became badly swollen and in the middle of June the weight of the body could not be borne upon it. The sharp pain had changed to a burning sensation and the limb had a heavy "blocky" feeling. The limb was very cold, but when heat was applied she could not feel it. At this time the pain was so severe that sleep was an impossibility. The $3 d$ of July she had what her daughter called a shock. There was complete prostration for several hours. It was three or four days before the feeling of numbness passed away.

At this time the foot was badly swollen, purple spots appeared, as if the foot was cold; these spots would disappear by rubbing and the natural color would returu. By the middle of July the top of the foot was discolored and water.blisters appeared. The burning sensation was very severe, the blisters increased in size and number while the toes were very cold and seemed dead.

This condition continued to increase until two thirds of the foot became gangrenous. In the latter part of July, 1896, I saw the patient in consultation with the attending physician. She was a woman 47 years of age, fleshy, and had had one child, daughter, about 20 years old. She had enjoyed good health up to the time of this sickness. There was no disease of the kidneys, and no evidence of arterial degeneration.

On examination $I$ found, what her physician had discovered some time before, a fibroid tumor of the uterus, rapidly growing, with thick and rigid abdominal walls pressing the tumor firmly against the iliac vessels. It was the right foot that was gangrenous, and the history showed that she was most comfortable when lying on the right side, and this was the position which she had occupied the most of the time while in bed. The case seemed well nigh hopeless. The woman was weak and almost helpless from her long sufferings, the tumor of the uterus was large and rapidly growing, the gangrene, while not rapidly extending, had destroyed nearly the whole foot. In this condition she was brought to the Maine General Hospital, Aug. 3, 1896, as my private patient. She was kept in the hospital one week before the operation for rest and preparatory treatment. At this time two thirds of the foot were dry and mummified and the line of demarkation was well-formed.

A ugust 10, one wesk after her admission to the hospital, I removed the tumor including the uterus and its appendages. The patient made a rapid and uninterrupted recovery from the hysterectomy, and in two weeks from the first operation, I am. putated the leg at the junction of the middle with the lower third by Teale's method. This wound healed promptly by first intention without a drop of pus or a blush of redness. Sheleft the hospital in five weeks from the time she entered, with the wounds entirely healed and rapidly gaining in strength. In about three months after she went home she was fitted with an artificial limb, and at this time, nine months after the operation, is entirely well.

As this was the first case of the kind I had ever seen I was anxious to know what had been the experience of other surgeons, consequently I wrote to the $\mathrm{Na}$. tional Bureau of Medical Bibliography at Washington, and received the following reply:

Washington, D. C., Feb. 26, 1897.

Dear Sir:--In response to your letter of the 18 th inst. we send you herewith reports of all the cases of gangrene of the lower extremities resulting from uterine fibroids that we have 
been able to find. We made an exhaustive search through all the literature of gangrene, cases of, and tumors, uterine, complications of, without finding any additional cases."

Pott's Gangrene from Ovarian Tumor.-Dr. Henry Fitzgibbon. (Brit. Med. Jour., Lond., 1876, I, 116.) Dr. Fitzgibbon gave the history of a case of Pott's senile gangrene which had run to an unusual course; and exhibited the specimens. A female, upward of 70 years of age, was admitted in to hospital in March, 1875, with gangrene of the fourth toe of the left fort. The case presented the usual symptoms of the disease as described by Pott. Her bowels were constipated, and there was a tumor in the left iliac region, which was believed to be due to an accumulation of feces. Treatment based upon this diagnosis produced a marked diminution in the size of the tumor. The disease extended in the foot (which, however, preserved a higher temperature than the unaffected one) to the ankle-joint, when suddenly the pain ceased, and the foot recovered, the toes alone becoming mummified, and consequently separating. It was ascertained that the abdominal tumor, whieh was still perceptible, had an old history; and the patient informed Dr. F. that she had been under treatment some years previously for an "uterine tumor." She was discharged in good health after being six months in the hospital. Five months subsequently she was readmitted. Her whole foot then looked gangrenous; the disease extended rapidly up the limb; she had black vomit, great abdominal pain, and died. A large densely fibrous tumor of the left ovary was found lying on, and pressing upon, the common iliac artery. The heart and vessels down to the line of demarkation, which had formed midway between the ankle and the knee, were healthy. Below this there were some plates of atheroma in the posterior tibial artery. Dr. F. believed that the circulation in the left lower extremity had been interfered with by the pressure of the tumor on the iliac artery, which was increased by the accumulation of feces also exerting pressure in the same direction. The removal of the latter factor by treatment allowed the partial recovery in the first instance; and a recurrence of pressure from a reaccumulation of feces, occasioned, he considered, a recurrence of the disease.

Gangrene of Leg; Polypus Uteri and Removal; Amputation.-J. Cooper Forster, M.D. Guy's Hosp. Rep., London, $1875,3, \mathrm{~S}, \mathrm{XX}, 79$.) Mary B., aged 45, widow, was admitted into charity ward on Dec. 31, 1873. Family history good, always had good health. Fourteen days ago, in the night, her foot got cold and ached : next morning all the toes of that foot were quite white and cold; she used a liniment and wrapped the foot up in warm flannels. In eight or ten days the toes began to get black; this spread along the foot and up the leg. She has not been exposed to great cold, but generally loses a large quantity of blood when menstruating.

On admission.-Is delicate looking; the toes, dorsum of foot, and front of lower half of right leg, are quite black and cold, and she has very little feeling in those parts; femoral artery normal. She has also a large growth occupying the region. Leg dressed with carbolic acid and wrapped in cotton wool.

January 8. Chloroform given. Dr. Phillips removed a polypus which was attached to uterus near os. It was very nearly as large as the head of a fetus, and was cut away by scissors; no bleeding.

January 19. There is a well-marked line of demarkation on leg; the gangrene has not spread since she came in, but there is some discharge from it.

January 20. I amputated through the knee-joint; anterior and posterior flaps made; Esmarch's bandage used; scarcely any bleeding.

January 23. Stump dressed under spray; then wrapped in gauze soaked in carbolic oil and a back splint applied; there is rather a free discharge.

January 28. Dressed as before. Stump has begun to slough. She suffers from cough and expectorates a good deal of thick mucus.

February 6. Now has a bed-sore on right buttock, about 4 inches by 3 in size, and filled with slough; lies on a water bed. Discharge less and of a healthy kind.

March 3. Stump nearly healed, bed sore looking better, sits up a little daily.

March 9. Two other bed-sores appeared. No albumin in urine, appetite bad, looks anemic.

April 6. Confined to bed again and takes very little food. A pril 20. Suffers from diarrhea. Sores looking more unhealthy, and increasing in size. Takes no meat now.

May 12. Lives almost entirely on brandy and milk. Bedsores continue to look very unhealthy.

May 21. Died this morning.

Gangrene of the Right Leg.-Amputation. Death fifty. one hours afterward. Large fibrous tumor of the uterus compressing the iliac vessels, (old disintegrating clot in lof a aricle, (embolic) obstruction of abdominal aorta and iliac arteries with coagulum. Case under care of Mr. Hulke. (Med. Times and Guzette, London, 1863, II, 142.) A sallow, dark complexioned woman, aged 55, was admitted into Middlesex Hospital, Bird Ward, April 1, 1863, with moist gangrene of the right leg, which terminated abruptly by a distinet line at the knee. For a short distance above this, particularly in the ham, the tissues were edematous, and the skin had a slight dusky, purplish tint, from stagnation of the capillary circulation. Severe pain in toes. Lower part of abdomen contained a solid oval tumor lying across the middle line, and reaching nearly as high as the umbilicus. Both in front of it, and in the flanks, percussion elicited a clear sound. The liver was not enlarged. The urine was free from albumin. T'here was no edema of the left thigh or labia. The heart acted very irregularly, four or five beats, then an intermission, then a double beat-so that the pulse could not be accurately counted; it was estimated at 120 ; no bruit indicating valvular disease was noted. Her general condition was one of great depression.

She stated that since childhood, when her left leg was amputated for whiteswelling, she had never had any grave illness till last Christmas, when, not feeling well, and discovering the tumor in her abdomen, she underwent a course of treatment for a supposed abdominal dropsy. After pursuing this for a fortnight, in the middle of January a bleb appeared on the instep, which was followed shortly by a discoloration that gradually crept up the leg.

Her temperate habits, apparent freedom from organic heartdisease, and from disease of the kidneys, made it improbable that the gangrene had a constitutional origin; while the suddenness of its occurrence strongly pointed to a local origin, and this Mr. Hulke thought might be the compreasion of the right common iliac vessels by the uterine tumor, and their consequent obstruction with coagula.

On the following day after admission amputation was done in the lower third of the thigh. There was little bleeding, the main vessels being plugged with coagula. At 10 o'clock, same evening the operation did not seem to have added to the pa. tient's depression. Pulse 100; sleeping; had taken beef tea and tablespoonful of brandy every hour. Next day stump had shrunken much. There had been free oozing of serum from it and there was a want of action, but no appearance of an extension of the gangrene. Continued to take nourishment. Toward evening restlessness and sickness came on, pulse rose to 120 and she died on the evening of the second day.

At the examination of the body a large fibroid tumor of the uterus was found, consisting of several lesser and two principal masses. Of these larger masses, one was connected with the back of the uterus and filled the pelvis, flattening the rectum and bladder. The other sprang from the fundus uteri. It measured more than 7 inches in diameter and lay upon the promontory of the sacrum and lower lumbar vertebræ, over the aorta and vena cava. The aorta, for over two inches above its bifurcation, the common, the internal, and the external iliac arteries for half their lengths, were plugged with solid coagula, which were prolonged in a tapering form into the distal halves of the last named vessels, nearly as far as Poupart's ligament. The oldest coagula were those in the internal and common iliac arteries and in the aorta. The distal halves of the external iliac arteries, which were incompletely filled with coagulum, were fully one third smaller in diameter than the proximal halves, which were completely plugged. The superficial femoral artery, for two inches above where it had been divided in amputation, was plugged with a fibrinous clot, above which this and the common femoral artery were pervious, containing only scattered linear clots. Their caliber was diminished. The vein was plugged for the same distance from the face of the stump as the artery. Above the clot it was distended with black, treacly, fluid blood. The external, internal and common iliac veins, and the vena cava inferior were empty and collapsed. Many of the tissues of the thigh were edematous. Small ves. sels were plugged, and examination of the limb showed that the popliteal artery and vein were plugged as far as their division, beyond which the disorganized state of the tissues pre vented their being traced. The ureters and pelves of the kidneys were dilated, evidently from the uterine tumor damming back the urine. The lungs were edematous, their anterior and lower borders were emphysematous, and their apices bore puckered scars. The heart was large and flaccid; its right side and left ventricle contained yellow jelly-like fibrinous clots, but the appendix of the auricle enclosed an old clot which adhered firmly to its walls. The exposed surface of this clot was cheesy, friable and rough, while its interior was broken down and pulpy. Although direct proof was wanting, for no distinct and 
separate emboli were distinguishable in the coagula contained in the aorta and iliac arteries, it is likely that the infarction of these arteries began by the interception of portions detached from the disintegrating clot in the heart, at those points where the arteries were narrowed by the pressure of the uterine tumor.

The method of hysterectomy which I have employed for many years and which is entirely satisfactory is as follows: The patient is prepared for the operation in the usual way. Just before the operation, immediately preceding the administration of ether, a pint of warm water with four ounces of wine is injected into the rectum. This is absorbed during the operation and supplies, in part at least, the blood lost during the operation and prevents shock, which is liable to occur when much blood is lost. I consider this a great safeguard against exhaustion following any prolonged operation where there is likely to be a considerable loss of blood. I always use the catgut for ligatures and sutures, and much prefer it to all others. The catgut which I use is Am Ende's No. 8. The morning of the operation the catgut which is to be used is sterilized by putting it into 95 per cent. alcohol in a wide-mouthed bottle, the stopper being loosely put in, the bottle is put into an Arnold sterilizer, where it remains about ten minutes - the bottle must be full of alcohol and not allowed to boil down and expose the catgut. If necessary, alcohol must be added, in order to keep the catgut covered, otherwise it will be spoiled by the heat.

Am Ende's catgut, prepared in this way, I consider perfectly sterile and feel safe in using it in all abdominal operations. To my mind the absorbable ligature is immensely superior to the silk which is generally used. I have used it for twenty years in all $\mathrm{my}$ abdominal work and I have never regretted it. It does not slip if properly used, it is not absorbed too soon and to me it is a great satisfaction to feel that the ligature will be absorbed in two or three weeks and no foreign body is left in the cavity or wound.

All things being ready, an incision is made in the usual way large enough for the removal of the tumor without too much stretching of the tissues. I think a mistake is often made in trying to work in the abdominal cavity through an opening altogether too small. Much more harm is done in this way than would result from a slight increase in the length of the incision. After the tumor is exposed a large curved needle armed with a strong silk ligature is thrust through the fundus of the fibroid and the ligature drawn through and formed into a loop, and this is used for making traction. By the aid of this loop the tumor is slowly and carefully drawn out through the opening and gradually pulled up so as to stretch the broad ligaments and vagina and thus secure as much tissue for the pedicle as possible.

Sterilized gauze is now packed around the tumor to prevent the intestines from protruding and to protect them from injury. This step having been taken I am now ready to commence the removal of the tumor, including the uterus and its appendages.

A pair of large curved Spencer Wells forceps grasp the broad ligament below the ovary. Instead of the forceps a strong silk ligature may be used, After the ovarian artery has been secured in this way, a curved needle armed with No 8 catgut prepared as above directed is passed through the outer edge of the broad ligament one inch or more below the Wells clamp or silk ligature, taking in as much tissue as can be securely tied and no more. If too much tissue is included in the first stitch the ligature is liable to slip when the tissues are divided and troublesome hemorrhage will occur.

I consider this precaution very important. The ligature is drawn through, leaving eight or ten inches of the distal end of the ligature to use in tying as the operation goes on. The ligature is tied very firmly and a second stitch is taken and before it is tighened the tissues are divided far enough above the catgut suture so that there shall be no danger of the tissues slipping through the loop of suture; and the cut extending up to but not beyond what is included in the second stitch, then the second looped stitch is tightened and made fast by tying to the distal end, which has been left long for this purpose. This process is carried on step by step, transfixing and tying and cutting, but always keeping the stitching a little in advance of the cutting so that the blood vessels are included in the suture before they are cut. This process is carried on until the uterine artery is included in the stitch and divided. At every step or two the ligature is fastened by tying to the distal end. If this rule is observed there is no possibility of the suture becoming loosened. When one side is secured in this way the operator changes sides with his assistant and the opposite side is tied and cut in the same way. When both broad ligaments are severed down to and including the uterine arteries the cervix is divided in the form of a wedge with the apex downward. Before dividing the cervix as indicated above, a flap of peritoneal membrane is turned down from the anterior and posterior surface of the uterus long enough to cover the stump of the cervix after its division and stitching. This wedge-shaped cavity is closed by bringing the cervical tissue together with the same catgut that has been used for stitching off the broad ligaments. Then a curved needle armed with a smaller catgut, No. 2, is used to bring together the flaps of serous membrame over the stump. When this is completed the divided cervix is entirely covered with peritoneum, leaving but very little raw surface within the peritoneal cavity. The abdominal cavity is now washed out with sterilized water, the abdominal incision closed, dressings applied and the operation is completed. I firmly believe that this is the ideal method of making hysterectomy. I much prefer it to the vaginal route, even for the removal of small growths requiring the removal of the uterus. The abdominal route gives one an opportunity of inspecting the uterus and its appendages and enables the surgeon to better decide what should be done, whether a myomectomy or hysterectomy. If there is malignant disease of the cervix and a hysterectomy is decided upon the vaginal route is to be preferred, as it enables the surgeon to remove the surrounding mucous membrane if it is involved in the disease.

In view of the fact that very many of these tumors are so rapid in their growth as to entail serious risks to life from the compression of other organs, from their interference with the normal functions of life, from the pains and disabilities they entail or from the profound anemia caused by persistent and profuse hemorrhage, it becomes evident that something more than an expectant plan of treatment must be instituted.

While it is true that many women with uterine fibromata go through many years suffering but little inconvenience, there is always more or less danger to the life and well-being of the patient. There is dan- 
ger of cystic degeneration, which takes away the hope of total disappearance by involution. There is also danger of the occurrence of septic infection with suppurative and gangrenous processes threatening the life of the patient. Growths springing from the cervical portion and extending between the layers of the broad ligaments occasion early and severe symptoms from pressure upon adjacent pelvic viscera. Submucous growths have a special danger from the hemorrhages which they induce. Sarcomatous degeneration of fibromyomata has been reported in a number of instances. It must be acknowledged that the prognosis of a growing fibroid is always a serious one. Such a growth is liable to cause death through the exhaustion consequent upon renal, cardiac or digestive disturbances; through the prolonged anemia or finally through septic or malignant changes in the tumor itself. In a large proportion of cases in which life is not destroyed the presence of these growths very greatly restricts the usefulness of the patient, prevents her from gaining a livelihood and entails upon her a prolonged condition of invalidism.

In view of these facts as stated above and in view of the less mortality which follows hysterectomy in the hands of competent operators, I believe the operation should be performed much more frequently than has been recommended by many surgeons. At the last International Medical Congress, Martin of Berlin affirmed that the total extirpation of the uterus would soon be accepted as one of the principal operations for the surgical treatment of uterine fibromata. Martin's series of twenty-six cases presented only one death - a mortality of 3.8 per cent.; Ott, twenty-four cases with one death; Bantock, twenty-three cases with one death; Carle, twenty cases with one death; Zweifel, ninety-three cases with three deaths; Leopold reports twenty cases with no death, and mentions Brennecke's report of nineteen cases with no death, making in all 225 cases with six deaths-a mortality of 2.6 per cent In Europe, five years ago, the mortality shown by the same class of operators was 25 per cent., while now they show a mortality of less than 8 per cent. In the United States, where the tendency is toward the operation of complete hysterectomy, in 281 united cases, three years ugo, there were but 22 deaths-a mortality of but 7.8 per cent. I have no doubt that the mortality is considerably less at the present time than it was three years ago. If this paper shall be the means of calling out a free discussion of this important subject, and shall cause to be put on record other cases of a similar nature I shall feel amply repaid for the labor in preparing it.

\section{GYNECOLOGY IN BERLIN.}

A. MACKENRODT.

BY JOSEPH RILUS EASTMAN, M.D. INDIANA POLIS. IND.

A. Mackenrodt is especially notable for his originalness. As a younger member of the Berlin Gynecological Society, he shies his castor with unaccustomed aggression before his seniors in age and rank, and is therefore unpopular. It was Mackenrodt (Dührrsen to the contrary notwithstanding) who introduced the ill-fated vaginal fixation for uterine retrodisplacements. $\mathrm{He}$ is the only continental exponent of igniextirpation for carcinoma uteri and of bloodless enucleation of the uterus for intractable postclimacteric inflammations and smaller fibromata. Under the im. pulse of the condemning reports of Paul Strassmann and others who had confined women with vaginally fixed uteri, "Mackenrodt's operation," after a short life, was relegated, as is well known, to comparative obscurity. Dührrsen still defends it qualifiedly, and the writer has seen A. Martin make the operation repeatedly and recently, but Martin places the uppermost of the three sutures not higher than a point four and one-half centimeters below the vertex of the fundus uteri. Mackenrodt himself having been driven to sectio Cæsaria after vaginal fixation in plural instances, forsook the method, convinced of its unfitness by the testimony of his own experience.

In its stead he is developing a new operation, a vesico-fixatio, by which it is sought to fix the fundus of the uterus over the fundus of the bladder by means of a flap of the latter's peritoneum. He shows by charts and frozen sections that the proversio-flexio so secured and maintained corresponds closely to the normal anatomic position. Two women operated on by this method have borne sound children at term. The technique is as follows: With the patient in the back posture, the anterior lip of the portio is seized with a double tenaculum and drawn forward and downward as for anterior colporrhaphy. A split is then made through the anterior vaginal mucosa, extending in the median sagittal line, from the anterior utero-vaginal junction forward, half way toward the meatus urethræ. The septum vesico-uterinum and the vesico-uterine reflection of peritoneum are successively exposed and divided transversely. The tenaculum in the anterior lip is then replaced by a guy ligature, and the portio is pushed upward and backward to force the vagina conversely forward and downward. To bring the fundus into the vaginal incision double tenaculæ are used. With these one "climbs" upward along the anterior uterine surface, applying each higher than the last, until the vesical peritoneum, which has been peeled loose as high up as possible, may be laid flap-like over the fundus uteri and stitched fast. The peritoneum is drawn as a curtain between the operator and the fundus, the stitches being applied into the latter "through the curtain." The fundus is now released and the anterior vesical flap of the septum vesico-uterinum is sutured into the muscular uterus as high up as the internal os, a centimeter higher than its anatomic attachment, to the end that the fundus may be held more securely forward. An adhesive peritonitis is expected to provide permanent fixation.

In a communication to the Centralblatt für Gynecologie, 1895 , No. 6, Mackenrodt took the position that adequate use of the glowing cautery offers the only hope for improvement in the statistics of lasting results after extirpation for carcinoma uteri. He recommended that the entire operation be made with the cautery, that the entire wound surface be charred, the goal sought being prevention of inoculation infection. $\mathrm{He}$ maintained that even in that instant when the tissues are divided, the wound surface must be protected against the invasion of cancer germs, and that such protection is only possible when all dissecting is done with the Paquelin. "Methods in which the cautery supplements the knife, ligature or clamp are illusory." In an experience of thirty igni-extirpations, Mackenrodt claims not to have had a single recurrence, the post operationem period of observation varying between one and two years; nor was any patient lost from shock. 